\title{
Gruesome twosome kukri rippers: Oligodon formosanus (Günther, 1872) and O. fasciolatus (Günther, 1864) eat Kaloula pulchra Gray, 1831 either by eviscerating or swallowing whole
}

\author{
Henrik Bringsøe ${ }^{1}$, Maneerat Suthanthangjai ${ }^{2}$, Winai Suthanthangjai ${ }^{2}$, \\ Jo Lodder ${ }^{3}$, Navapol Komanasin ${ }^{4}$ \\ 1 Irisvej 8, DK-4600, Køge, Denmark \\ 2 Environmental Science Program, Department of Applied Science, Faculty of Science and Technology, Loei Rajabhat University, Loei, 42000, Thailand \\ 3 Wang Tong Village 63a, Lantau Island, Hong Kong \\ 425 Mu 10, Ban Phue, Ban Phue District, Udon Thani, 41160, Thailand \\ http://zoobank.org/E188E834-6900-418D-9D4E-A521B193825F
}

Corresponding author: Henrik Bringsøe (bringsoe@email.dk)

Academic editor: Günter Gollmann • Received 2 January 2021 • Accepted 3 February 2021 • Published 15 February 2021

\begin{abstract}
Predation on adult microhylid frogs Kaloula pulchra by two closely-related colubrid snakes is described, based on two observations of Oligodon formosanus in Hong Kong and one observation of $O$. fasciolatus in Thailand. In two instances, $O$. formosanus was observed cutting open the abdomen of this anuran species. In one case, it performed repeated rotations about its own longitudinal body axis ("death roll") while its head was inserted into the frog's abdomen. The purpose of this behaviour was probably to tear off organs and swallow them. Once $O$. fasciolatus was observed catching and swallowing $K$. pulchra whole. In that case, the snake also made a series of rotations while it maintained its firm grip in the frog's belly. It is concluded that, for these two closely-related kukri snakes, prey size is crucial for determining whether the gape width allows large preys to be swallowed entire.
\end{abstract}

Key Words

Anura, behaviour, Colubridae, death roll, Hong Kong, Microhylidae, posterior maxillary teeth, rotational feeding, Squamata, Thailand

\section{Introduction}

Recently, we described a unique and hitherto unknown feeding behaviour in a kukri snake, Oligodon fasciolatus, which cuts open the abdomen of toads (Duttaphrynus melanostictus) and eats some of its organs (Bringsøe et al. 2020). That was documented in three cases, but in a fourth case, a semi-adult D. melanostictus was swallowed whole. In this report, three additional observations on feeding behaviour in kukri snakes are provided by contributions from citizen science. They are supported by photographic documentation and cor- respond well with our earlier observations, though the evidence is not as strong.

To date, 83 species of kukri snakes of the genus Oligodon have been described, being widely distributed in southern Asia (Uetz et al. 2020; Pauwels et al. 2021). Oligodon formosanus, the Taiwanese Kukri Snake, ranges throughout southern China, Taiwan and northern Vietnam, whereas Oligodon fasciolatus, the Small-banded Kukri Snake, occupies a more south-western distribution covering south-eastern Myanmar, Thailand, Cambodia, Laos and Vietnam (Zhao and Adler 1993; Nguyen et al. 2009; Bringsøe et al. 2020). They share the appearance 
of being robust, small-headed, relatively short (normally less than $100 \mathrm{~cm}$ total length) and having a brownish ground colour, often tinged yellow-olive, greyish-brown or reddish-brown. Oligodon formosanus has 19 mid-body scale rows and often a broad vertebral stripe, as opposed to $O$. fasciolatus having 21-23 mid-body scale rows (Kuntz 1963; Karsen et al. 1986; Das 2010; Green 2010; Bringsøe et al. 2020).

In all three cases we observed, the prey of $O$. formosanus and $O$. fasciolatus was Kaloula pulchra, Painted Burrowing Frog or Banded Bullfrog, which is widely distributed in Southeast and East Asia, in the west reaching Bangladesh and north-eastern India (Zhao and Adler 1993; Sengupta et al. 2009; Mathew and Sen 2010; Hasan et al. 2014; Vassilieva et al. 2016; Niyomwan et al. 2019). It is abundant in urban and rural areas and a variety of forest habitats.

\section{Methods}

The three observations are presented in chronological order as follows.

Observation \#1 involving an adult Oligodon fasciolatus and an adult Kaloula pulchra was made on 15 September 2020 from approx. 06:10 to 06:45 h. Locality: Outskirts of Ban Phue Village, Udon Thani Province, Northeast Thailand. Coordinates: $17^{\circ} 40.95^{\prime} \mathrm{N}$, $102^{\circ} 27.85^{\prime} \mathrm{E}$, altitude approx. $185 \mathrm{~m}$ a.s.l. Habitat: Rural area along the outer wall of a building in a factory site. It was approx. $20 \mathrm{~m}$ from a pond, surrounded by paddy fields with rice, rubber and cassava plantations and abandoned land. Observations, as well as photos and nine video recordings, were made by Navapol Komanasin. The total duration of the video sequences was 188 seconds and they were made from 06:16 to $06: 36 \mathrm{~h}$.

Observation \#2 involving an adult Oligodon formosanus and an adult Kaloula pulchra was made on 2 October 2020 from approx. 09:05 to 09:45 h. Locality: Wang Tong Village, south-eastern part of Lantau Island, Hong Kong. Coordinates: $22^{\circ} 16.30^{\prime} \mathrm{N}, 113^{\circ} 59.87^{\prime} \mathrm{E}$, altitude $5-7 \mathrm{~m}$ a.s.l. Habitat: the observer's garden located in a residential neighbourhood with a nearby stream. Observations, as well as photos, were made by Jo Lodder and five video recordings were made by Jo Lodder and Jonathan Rotbart. The clocks of the two video cameras were not synchronised as there was a time difference of approx. two minutes. There were overlaps in the video clips of the two video cameras, but the overlaps were fully identified on the basis of the human voices in the background and the visual actions of the snake and the frog. The total duration of unique video sequences was approx. 143 seconds and they were made from approx. 09:10 to 09:13 h.

Observation \#3 involving an adult Oligodon formosanus and an adult Kaloula pulchra was made on 8 October 2020 at approx. 17:30 h. Locality: Caribbean Coast, northern part of Lantau Island, Hong Kong. Coordinates: $22^{\circ} 17.52^{\prime} \mathrm{N}, 113^{\circ} 57.08^{\prime} \mathrm{E}$, altitude $2-3 \mathrm{~m}$ a.s.l. Habitat: an urban park with recreational areas approx. $40 \mathrm{~m}$ from a

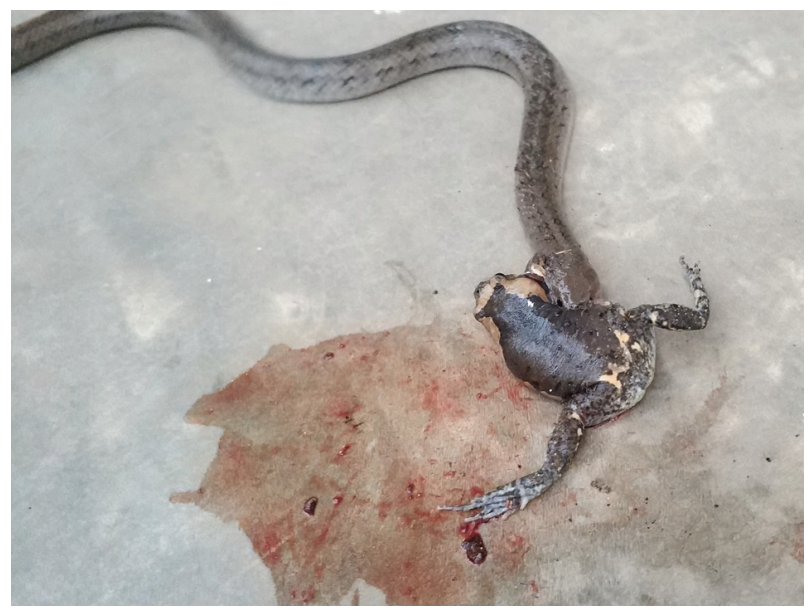

Figure 1. Oligodon fasciolatus maintained a firm grip in the right side of the belly of Kaloula pulchra. Blood and possibly some organs tissue appeared. Observation \#1, Ban Phue, Thailand, 15 September 2020. Photo NK.

highway and approx. 60-70 m from high-rise blocks with residential flats. Observations and one video recording were made by Vince Natteri. The duration of the video sequence was 30 seconds and it was made at approx. 17:30 h.

Neither the snakes nor the frogs were touched by the observers at any time.

\section{Results}

\section{Observation \#1}

Initially, the adult Oligodon fasciolatus was startled by the sudden appearance of the observer just outside the building and retreated into a pile of empty oil cans. However, it apparently forgot its fright as it found an adult Kaloula pulchra underneath them and grabbed it in the belly, close to the lower part of the right side and the two individuals started struggling (Fig. 1). Initially the frog puffed up its body. During the initial phases of the struggle, as the frog resisted most vigorously, the snake was observed rotating repeatedly about its own longitudinal body axis. In two video sequences, a total of 11 rotations occurred, all counter-clockwise, as follows:

- In a 15 second video sequence, 8 rotations were made as the frog's body was puffed up, at 06:17 $\mathrm{h}$ (Suppl. material 1: Video A1).

- In another 15 second video sequence, 3 rotations were made as the frog's body was no longer puffed up, at 06:18 h.

The frog was solely observed ballooning or puffing up its body once, namely during the above video sequence at 06:17 $\mathrm{h}$ and continuing for a while afterwards. From the next sequence, starting approx. one minute later, this behaviour had ceased. During the entire struggle, the snake maintained its firm grip in the frog's belly. The frog was killed between 06:20 and 06:31 h. The snake's efforts 


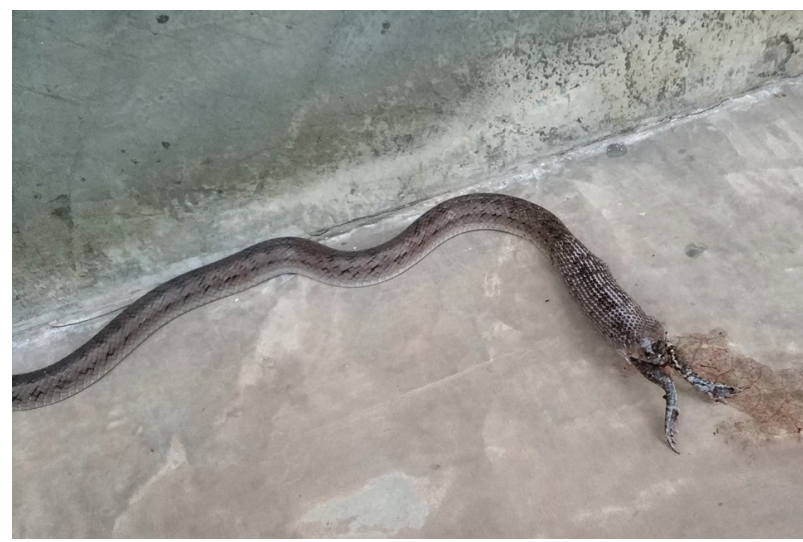

Figure 2. Eventually Oligodon fasciolatus swallowed the adult Kaloula pulchra whole. Observation \#1, Ban Phue, Thailand, 15 September 2020. Photo NK.

resulted in its teeth penetrating the abdomen to such an extent that blood and possibly some organ tissue appeared. Eventually, the frog was swallowed whole while still alive (Fig. 2; Suppl. material 2: Video A2).

\section{Observation \#2}

The adult Oligodon formosanus was observed as it appeared from a hole in the ground and caught the frog, Kaloula pulchra, passing by. Initially the snake bit and held the lower part of the belly of the frog which persistently struggled to escape by moving in circles. As the snake's tail and posterior part of the body were still in the hole, it managed to cut open the abdomen of the frog. Gradually, it inserted its head which went further into the abdomen (Fig. 3).

Additionally, the frog ballooned and puffed up its body by inflating its lungs during the first 40 seconds

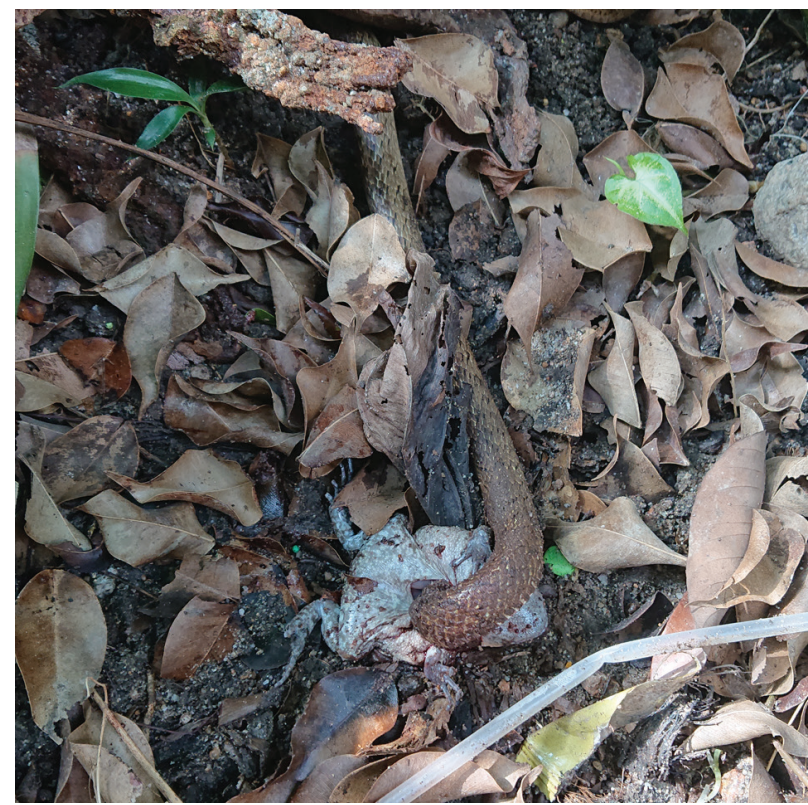

Figure 3. The head of Oligodon formosanus was inserted deep into the abdomen of Kaloula pulchra. Observation \#2, Wang Tong, Lantau Island, Hong Kong, 2 October 2020. Photo JL. of a 46 second video sequence of the attack (while the snake had inserted its head into the frog's abdomen). The snake and the frog were nearly motionless for the first 22 seconds, whereas a strenuous fight was observed for the remaining 24 seconds. What happened afterwards was not recorded.

During the 22 seconds of immobility, the frog's long fourth toe of the left hind foot moved up and down 21 times, i.e. at an average frequency of approx. 1 beat per second (Suppl. material 4: Video A4). Sometimes during the 22 seconds, the frequency was approx. 2.5 beats per second. No toe-moving was observed when the fighting was at its peak and the two individuals moved a lot.

Repeatedly during the fight, while the snake's head was inserted in the frog's abdomen, the snake rotated about its own longitudinal body axis (Fig. 4). In two video sequences, such rotations occurred in a total of 15 times, mainly clockwise, as follows:

- In a 90 second video sequence, 12 rotations were made clockwise as the frog was not ballooning its body from approx. 09:10 to 09:11 h (Suppl. material 3: Video A3).

- In a 46 second video sequence (see above), 3 rotations were made, first twice counter-clockwise, then once clockwise as the frog was ballooning its body (except the last 6 seconds) from approx. 09:12 to 09:13 h (Suppl. material 4: Video A4).

Finally, the inflation of the frog subsided and the frog shrunk to normal size or possibly less. During the approx. 40 minutes of observation, it was not possible to ascertain whether the snake ate any of the frog's organs, but no attempt to swallow the entire frog was noticed. The observer left the situation before it was finished. Nevertheless, as he returned later that day, the frog was no longer there, so it might have been eaten by the kukri snake.

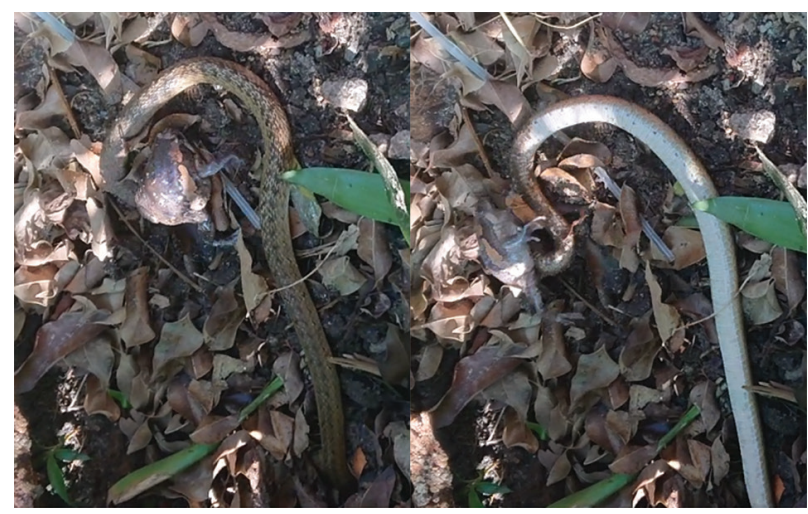

Figure 4. While the head of Oligodon formosanus was inserted into the abdomen of Kaloula pulchra, the snake performed repeated rotations about its own longitudinal body axis. The frog and the anterior part of the snake are in the top of each photo, close to the plastic drinking straw. Left: dorsal surface uppermost. Right: ventral surface uppermost. Observation \#2, Wang Tong, Lantau Island, Hong Kong, 2 October 2020. Photos (from video) JL. 


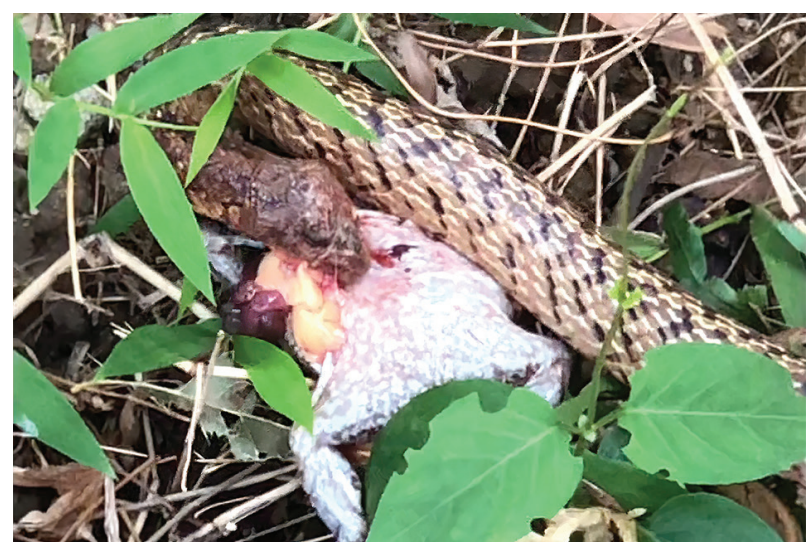

Figure 5. Oligodon formosanus chewed organs of Kaloula pulchra after they had been forced out of the abdomen. Observation \#3, Caribbean Coast, Lantau Island, Hong Kong, 8 October 2020. Photo (from video) VN.

\section{Observation \#3}

The adult Oligodon formosanus was observed biting or chewing organs of an adult Kaloula pulchra which had first been cut open. The snake worked energetically and several organs of the frog had been forced out. They were exposed and visible (Fig. 5; Suppl. material 5: Video A5). At that time, the frog was dead though we cannot say whether it was alive when the snake found it. The observation lasted approx. 2 minutes in total, but the feeding continued after the observer had left.

\section{Discussion}

Oligodon formosanus, O. fasciolatus and K. pulchra are common in disturbed areas around human settlements (Kuntz 1963, Vassilieva et al. 2016, Niyomwan et al. 2019, Bringsøe, Suthanthangjai and Suthanthangjai, unpubl.) which increases the chances for predation on $K$. pulchra in such environments.

These three cases indicate that $K$. pulchra forms an important prey for these two species of kukri snakes. Oligodon formosanus has been observed feeding on frogs, lizards (including road-kill), squamate eggs and turtle eggs (Hwang et al. 1965; Reitinger 1978; Shi and Zheng 1985; Karsen et al. 1986; Toriba 1987; Coleman et al. 1993; Ota and Lin 1994; Huang et al. 2011; Messenger 2017). Qi (pers. comm.) has given us a photo of a third case of $O$. formosanus preying on $K$. pulchra, taken in Guangzhou, Guangdong Province, China, April 2017, which supports our assumption that this anuran species is a common prey of $O$. formosanus. The statement of Coleman et al. (1993) that $O$. formosanus feeds almost exclusively on reptile eggs is probably oversimplified. Predation on items other than eggs has been recorded over a major part of the distribution, although some geographic variation may exist. Further investigation will be needed due to the lack of quantitative data. The diet of $O$. fasciolatus is more poorly documented. Apart from our recent paper (Bringsøe et al. 2020) on this species eating D. melanostictus, Niyomwan et al. (2017) mention that it feeds on reptile eggs (which it cuts open with its teeth and then swallows the contents), rodents, frogs and small snakes. Moreover, W. Suthanthangjai (unpubl.) observed in Loei Province, Thailand, a semi-adult $O$. fasciolatus which swallowed an adult Fejervarya limnocharis in December 2016 and an adult $O$. fasciolatus swallowing a juvenile Hoplobatrachus rugulosus in August 2020; in both cases the frogs were swallowed whole.

One of them, O. fasciolatus, is known to eat toads, Duttaphrynus melanostictus, which may either be eviscerated alive and their organs eaten or swallowed whole (Bringsøe et al. 2020). A different and wider range of prey items has been documented for $O$. formosanus, namely lizards (including road-kill), turtle eggs and squamate eggs (Hwang et al. 1965; Toriba 1987; Coleman et al. 1993; Ota and Lin 1994; Huang et al. 2011; Messenger 2017).

Kaloula pulchra can exude highly sticky secretions which are likely used to deter some predators (Evans and Brodie 1994; Hasan et al. 2014; Purkayastha 2015; Niyomwan et al. 2019). Wei et al. (2013) observed that skin secretions of $K$. pulchra hainana induce erythrocyte haemolysis by means of a pore-forming mechanism in the bilayer lipid membrane. Furthermore, it is known that $K$. pulchra can swell its bulky body, by inflating the lungs like a balloon, as an anti-predator mechanism (Hasan et al. 2014; Purkayastha 2015; Niyomwan et al. 2019). Nevertheless, Xenopeltis unicolor has been observed constricting and swallowing $K$. pulchra (Gilbert and Goodyear 2019). A third defensive behaviour was reported by Purkayastha (2015) as K. pulchra vibrated its long fourth toe as the author held four individuals in his hands. In observation \#2 involving $O$. formosanus, the frog exhibited a similar behaviour of its left hind foot when the two individuals were otherwise immobile though the toe movements were not sufficiently rapid to be termed vibration.

In at least $O$. formosanus, the enlarged posterior maxillary teeth are apparently specialised for cutting reptile eggs and anuran skin. The posterior edge of these teeth is particularly sharp (Coleman et al. 1993). We postulate that this ability is essential for the behaviour of cutting through the abdomen of anurans and subsequently swallowing their organs.

Interestingly, in the two cases of $O$. formosanus, the snakes clearly cut open the abdomen of the frogs, whereas in the third case involving $O$. fasciolatus, the teeth inflicted minor punctures in the skin of the frog, but nevertheless the frog was swallowed whole. One essential question is whether $O$. formosanus eventually swallowed organs of $K$. pulchra in the manner that we have recently documented in $O$. fasciolatus preying on toads.

The two $O$. formosanus observations: In Observation \#2, the snake's head was so deeply inserted into the abdomen of the frog that it was not visible for approx. 20 minutes. This is an indication that the snake was in the process of eating organs. It is not unusual that a fight 
between a kukri snake and an anuran is time-consuming: in one case of our previous paper (Bringsøe et al. 2020), the fight, including pulling out and ingesting organs, took approx. three hours.

Another interesting behaviour observed in two cases was the snakes' repeated rotations about their own longitudinal body axis. In Observation \#1, spinning occurred while $O$. fasciolatus bit and held the belly of the frog, whereas in Observation \#2, O. formosanus performed rotations while its head was inserted into the abdomen of the frog (Fig. 3). Martins (1996) and Fiorillo et al. (2020) superficially reviewed neotropical snake species (14 colubrids and 1 boid) that perform rotational behaviour, though solely for the purpose of defence. This behaviour, also known as the "death roll", is especially well-known amongst crocodilians, for example, during feeding when they tear pieces from large prey items (Fish et al. 2007; Drumheller et al. 2019). Such feeding behaviour seldom occurs in lizards, such as Varanus albigularis (Krebs and Wünstel 2019). Predators with legs do not use their legs during rotational feeding, but usually they are held back against the body sides. Rotational behaviour, associated with eating large prey, has been documented in limbless, snake-like species, such as eels, caecilians and slowworms (Helfman and Clark 1986; Measey and Herrel 2006; Völkl and Alfermann 2007). In exceptional cases, Anguis spp. may exhibit axis spinning behaviour if two individuals are fighting over an earthworm. Since rotational feeding in connection with ingestion of oversized prey is generally used for reducing prey size, it is very likely that the body rotations of $O$. formosanus served the same purpose, i.e. tearing out organs to be subsequently swallowed. It should be mentioned that caecilians may also use such rolling behaviour even when the smallest prey items (first instar crickets) are taken (Measey and Herrel 2006).

In the four earlier cases where toads were either eviscerated and organs were eaten or swallowed whole by $O$. fasciolatus, no sign of feeding rotation was observed (Bringsøe et al. 2020), but that behaviour occurred in one of the new cases involving this species as the frog was swallowed whole.

In Observation \#3, which also involved O. formosa$n u s$, several organs of $K$. pulchra had been forced out of its body and the snake was chewing them throughout the short video sequence. We interpret this behaviour that it was in the process of swallowing them. That may be a lengthy process as mentioned above.

In contrast to Observation \#3 and Observation \#2, $O$. fasciolatus in Observation \#1 swallowed the adult $K$. pulchra whole without inserting its head into the frog's abdomen (although initial penetration by the teeth caused body fluids to appear), despite the fact that $O$. fasciolatus is adept at eviscerating toads alive to eat their organs. Thus, in these two species of kukri snakes, we believe that prey size is crucial in determining whether the gape width allows large prey to be swallowed whole. That also applies to $O$. ocellatus which is most probably resistant to toad toxins (Bringsøe and Holden 2021). This kukri snake lives in Vietnam, Cambodia, Laos and the easternmost Thailand.

Oligodon fasciolatus and O. formosanus are closely related and have been assigned to the $O$. cyclurus species group (David et al. 2008; Green 2010; Green et al. 2010). It may well be that species of this group or clade have developed the technique of eviscerating anurans to eat organs and slitting open reptile eggs with pliable shells to eat the contents. That behaviour has now also been described in a third species from that group, namely $O$. ocellatus, though the snake did not take out the bowel after it had pierced the toad's abdomen and inserted its head (Bringsøe and Holden 2021).

\section{Acknowledgements}

We are particularly grateful to Vince Natteri (Pinpoint Asia Limited, Hong Kong) who made his observation of $O$. formosanus eating $K$. pulchra available to us. Mark Hanger (Copenhagen, Denmark) made valuable contributions and reviewed the English language. Useful information was provided by Shuo Qi (Sun Yat-sen University, Guangzhou, China).

\section{References}

Bringsøe H, Holden J (2021) Yet another kukri snake piercing an anuran abdomen: Oligodon ocellatus (Morice, 1875) eats Duttaphrynus melanostictus (Schneider, 1799) in Vietnam. Herpetozoa 34: 57-59. https://doi.org/10.3897/herpetozoa.34.e62689

Bringsøe H, Suthanthangjai M, Suthanthangjai W, Nimnuam K (2020) Eviscerated alive: Novel and macabre feeding strategy in Oligodon fasciolatus (Günther, 1864) eating organs of Duttaphrynus melanostictus (Schneider, 1799) in Thailand. Herpetozoa 33: 157-163. https://doi.org/10.3897/herpetozoa.33.e57096

Coleman K, Rothfuss LA, Ota H, Kardong KV (1993) Kinematics of egg-eating by the specialized Taiwan snake Oligodon formosanus (Colubridae). Journal of Herpetology 27(3): 320-327. https://doi. org/10.2307/1565154

Daly JW, Noimai N, Kongkathip B, Kongkathip N, Wilham JM, Garraffo HM, Kaneko T, Spande TF, Nimit Y, Nabhitabhata J, Chan-Ard $\mathrm{T}$ (2004) Biologically active substances from amphibians: preliminary studies on anurans from twenty-one genera of Thailand. Toxicon 44(8): 805-815. https://doi.org/10.1016/j.toxicon.2004.08.016

Das I (2010) A Field Guide to the Reptiles of South-East Asia. New Holland Publishers, London, 376 pp.

David P, Vogel G, Pauwels OSG (2008) A new species of the genus Oligodon Fitzinger, 1826 (Squamata: Colubridae) from southern Vietnam and Cambodia. Zootaxa 1939: 19-37. https://doi.org/10.11646/ zootaxa.1939.1.3

Drumheller SK, Darlington J, Vliet KA (2019) Surveying death roll behavior across Crocodylia. Ethology Ecology \& Evolution 31(4): 329-347. https://doi.org/10.1080/03949370.2019.1592231

Evans CM, Brodie Jr ED (1994) Adhesive strength of amphibian skin secretions. Journal of Herpetology 28(4): 499-502. https://doi. org/10.2307/1564965 
Fiorillo BF, da Silva BR, Menezes FA, Marques OAV, Martins M (2020) Composition and natural history of snakes from Etá Farm Region, Sete Barras, south-eastern Brazil. ZooKeys 931: 115-153. https:// doi.org/10.3897/zookeys.931.46882

Fish FE, Bostic SA, Nicastro AJ, Beneski JT (2007) Death roll of the alligator: mechanics of twist feeding in water. The Journal of Experimental Biology 210: 2811-2818. https://doi.org/10.1242/jeb.004267

Gilbert E, Goodyear J (2019) Predation of Xenopeltis unicolor (Serpentes: Xenopeltidae) on Kaloula pulchra (Anura: Microhylidae) in Bangkok, Thailand. Tropical Natural History 19(1): 37-38. https:// li01.tci-thaijo.org/index.php/tnh/article/view/181199

Green MD (2010) Molecular phylogeny of the snake genus Oligodon (Serpentes: Colubridae), with an annotated checklist and key. Master of Science thesis, University of Toronto, $161 \mathrm{pp}$.

Green MD, Orlov NL, Murphy RW (2010) Toward a phylogeny of the kukri snakes, genus Oligodon. Asian Herpetological Research 1(1): 1-21.

Hasan MK, Khan MMH, Feeroz MM (2014) Amphibians and Reptiles of Bangladesh - a Field Guide. Arannayk Foundation, Dhaka, 191 pp.

Helfman GS, Clark JB (1986) Rotational feeding: overcoming gape-limited foraging in anguillid eels. Copeia 1986(3): 679-685.

Huang W-S, Greene HW, Chang T-J, Shine R (2011) Territorial behavior in Taiwanese kukrisnakes (Oligodon formosanus). Proceedings of the National Academy of Sciences USA 108: 7455-7459. https:// doi.org/10.1073/pnas.1101804108

Hwang M-h, Ho S-s, Chou, S-a, Hsieh T-t, Hu B-c (1965) Feeding habits of snakes from Chekiang. Acta Zoologica Sinica 17(2): 137-146.

Karsen SJ, Lau MW, Bogadek A (1986) Hong Kong Amphibians and Reptiles. Urban Council, Hong Kong, 136 pp.

Krebs U, Wünstel U (2019) Observations and experiments on "spinning behavior" in Varanus albogularis. Biawak 13(1): 54-61.

Kuntz RE (1963) Snakes of Taiwan. Quarterly Journal of the Taiwan Museum 16: 1-79.

Martins M (1996) Defensive tactics in lizards and snakes: the potential contribution of the Neotropical fauna. In: Del Claro K (Ed.) Anais do XIV Encontro Anual de Etologia. Sociedade Brasileira de Etologia, Universidade Federal de Uberlandia, Brasil, 185-199.

Mathew R, Sen N (2010) Pictorial guide to amphibians of North East India. Zoological Survey of India, Kolkata, [xii +] 144 pp.

Measey GJ, Herrel A (2006) Rotational feeding in caecilians: putting a spin on the evolution of cranial design. Biology Letters 2: 485-487. https://doi.org/10.1098/rsbl.2006.0516

Messenger KR (2017) Oligodon formosanus (Taiwan kukri snake). Diet / scavenging. Herpetological Review 48(2): 456-457.

Nguyen VS, Ho TC, Nguyen QT (2009) Herpetofauna of Vietnam. Edition Chimaira, Frankfurt am Main, 768 pp.

Niyomwan P, Srisom P, Pawangkhanant P (2017) Reptiles of Huai Kha Khaeng. Rabbit in the Moon Foundation, Rajaburi, 481 pp. [in Thai] Niyomwan P, Srisom P, Pawangkhanant P (2019) Amphibians of Thailand. Rabbit in the Moon Foundation, Rajaburi, 485 pp. [in Thai]

Ota H, Lin J-T (1994) Digestive tract contents of Oligodon formosanus and their implications on the adaptation for reptile-egg eating snakes. Journal of the Taiwan Museum 47(2): 75-78.

Pauwels OSG, Thongyai K, Chantong P, Sumontha M (2021) Two new kukri snake species (Colubridae: Oligodon) from the Nak- hon Si Thammarat Mountain Range, and addition of $O$. ocellatus to the fauna of Thailand. Zootaxa 4908(4): 537-557. https://doi. org/10.11646/zootaxa.4908.4.7

Purkayastha J (2015) Kaloula pulchra (banded bullfrog). Defensive behavior. Herpetological Review 46(3): 412-413.

Reitinger FF (1978) Common snakes of South East Asia and Hong Kong. Heinemann, Hong Kong, Singapore, Kuala Lumpur, 114 pp.

Sengupta S, Das A, Das S, Hussain B, Choudhury, NK, Dutta SK (2009) Taxonomy and biogeography of Kaloula species of eastern India. The Natural History Journal of Chulalongkorn University 9(2): 209-222.

Shi P, Zheng W (1985) Studies on feeding habits of the snakes of Mount Wuyi. Acta Herpetologica Sinica 4(2): 149-152. [in Chinese with English summary]

Toriba M (1987) Feeding behaviour of two species of the genus Oligodon from China. The Snake 19(1): 5-9.

Uetz P, Freed P, Hošek J [Eds] (2020) The Reptile Database. http:// www.reptile-database.org

Vassilieva AB, Galoyan EA, Poyarkov NA, Geissler P (2016) A photographic field guide to the amphibians and reptiles of the lowland monsoon forests of southern Vietnam. Edition Chimaira, Frankfurt am Main, 324 pp.

Völkl W, Alfermann D (2007) Die Blindschleiche - die vergessene Echse. Laurenti-Verlag, Bielefeld, 159 pp.

Wei S, Chi T, Meng A, Chen C, An T, Wang M, Zhang Y (2013) Characteristics of hemolytic activity induced by skin secretions of the frog Kaloula pulchra hainana. Journal of Venomous Animals and Toxins including Tropical Diseases 2013, 19: e9. https://doi. org/10.1186/1678-9199-19-9

Zhao E, Adler K (1993) Herpetology of China. Society for the Study of Amphibians and Reptiles, Oxford, Ohio, $521 \mathrm{pp}$.

\section{Supplementary material 1}

\section{Video A1}

Authors: Henrik Bringsøe, Maneerat Suthanthangjai, Winai Suthanthangjai, Jo Lodder, Navapol Komanasin

Data type: MP4 file

Explanation note: Oligodon fasciolatus in the initial phase of attacking Kaloula pulchra which is inflating its lungs. The snake makes eight counterclockwise rotations about its own longitudinal body axis as it is biting and holding the belly of the frog. Observation \#1, Ban Phue, Thailand, 15 September 2020 at $06: 17$ h. Recorded by NK.

Copyright notice: This dataset is made available under the Open Database License (http://opendatacommons.org/licenses/ odbl/1.0/). The Open Database License (ODbL) is a license agreement intended to allow users to freely share, modify, and use this Dataset while maintaining this same freedom for others, provided that the original source and author(s) are credited.

Link: https://doi.org/10.3897/herpetozoa.32.e62688.suppl1 


\section{Supplementary material 2}

Video A2

Authors: Henrik Bringsøe, Maneerat Suthanthangjai, Winai Suthanthangjai, Jo Lodder, Navapol Komanasin

Data type: MP4 file

Explanation note: Oligodon fasciolatus swallows Kaloula pulchra whole after having killed it. Observation \#1, Ban Phue, Thailand, 15 September 2020 at 06:36 h. Recorded by NK.

Copyright notice: This dataset is made available under the Open Database License (http://opendatacommons.org/licenses/ odbl/1.0/). The Open Database License (ODbL) is a license agreement intended to allow users to freely share, modify, and use this Dataset while maintaining this same freedom for others, provided that the original source and author(s) are credited.

Link: https://doi.org/10.3897/herpetozoa.34.e62688.suppl2

\section{Supplementary material 3}

\section{Video A3}

Authors: Henrik Bringsøe, Maneerat Suthanthangjai, Winai Suthanthangjai, Jo Lodder, Navapol Komanasin

Data type: MP4 file

Explanation note: Oligodon formosanus has, during its feeding attack, inserted its head into the abdomen of Kaloula pulchra as it performs 12 clockwise rotations (it is apparently in the process of making its thirteenth rotation as the video stops). Observation \#2, Wang Tong, Lantau Island, Hong Kong, 2 October 2020 from approx. 09:10 to 09:11 h. Recorded by Jonathan Rotbart.

Copyright notice: This dataset is made available under the Open Database License (http://opendatacommons.org/licenses/ odbl/1.0/). The Open Database License (ODbL) is a license agreement intended to allow users to freely share, modify, and use this Dataset while maintaining this same freedom for others, provided that the original source and author(s) are credited.

Link: https://doi.org/10.3897/herpetozoa.34.e62688.supp13

\section{Supplementary material 4}

Video A4

Authors: Henrik Bringsøe, Maneerat Suthanthangjai, Winai Suthanthangjai, Jo Lodder, Navapol Komanasin

Data type: MP4 file

Explanation note: Oligodon formosanus still has its head inserted into the abdomen of Kaloula pulchra. During the initial immobility of both individuals, the frog moves its long fourth toe of the left hind foot up and down 21 times. During the subsequent active struggle, the snake makes three rotations, first two counterclockwise, then one clockwise. Observation \#2, Wang Tong, Lantau Island, Hong Kong, 2 October 2020 from approx. 09:12 to 09:13. Recorded by Jonathan Rotbart.. Copyright notice: This dataset is made available under the Open Database License (http://opendatacommons.org/licenses/ odbl/1.0/). The Open Database License (ODbL) is a license agreement intended to allow users to freely share, modify, and use this Dataset while maintaining this same freedom for others, provided that the original source and author(s) are credited. Link: https://doi.org/10.3897/herpetozoa.34.e62688.suppl4

\section{Supplementary material 5}

\section{Video A5}

Authors: Henrik Bringsøe, Maneerat Suthanthangjai, Winai Suthanthangjai, Jo Lodder, Navapol Komanasin

Data type: MOV file

Explanation note: Oligodon formosanus has cut open the abdomen of Kaloula pulchra and has extracted several organs which it is biting and chewing and apparently in the process of swallowing. Observation \#3, Caribbean Coast, Lantau Island, Hong Kong, 8 October 2020 at approx. 17:30 h. Recorded by Vince Natteri.

Copyright notice: This dataset is made available under the Open Database License (http://opendatacommons.org/licenses/ odbl/1.0/). The Open Database License (ODbL) is a license agreement intended to allow users to freely share, modify, and use this Dataset while maintaining this same freedom for others, provided that the original source and author(s) are credited. Link: https://doi.org/10.3897/herpetozoa.34.e62688.supp15 